\title{
THORACIC SURGERY PREPARATION, PATIENT ELECTION, AND ITS MANAGEMENT DURING COVID-19 PANDEMIC: SURABAYA EXPERIENCES
}

\author{
Gerardo AK Laksono ${ }^{1)}$, Andreas MS Hutama ${ }^{1)}$, Paul L Tahalele ${ }^{2)^{* * * *}}$
}

\begin{abstract}
A novel coronavirus pneumonia outbreak began in Wuhan, Hubei Province, in December 2019. It has spread rapidly from China to worldwide. The COVID-19 pandemic of 2020 posed a historic challenge to healthcare systems around the world, healthcare systems needed to consider providing clinical services to other patients in need. The specialty of general thoracic surgery includes the management of serious diseases such as chest wall congenital anomaly, lung cancers, esophageal cancers, mediastinal tumor, chest wall infection, and trauma. Thoracic surgery is one of high risk procedure in this pandemic, however, a high level of evidence supports the surgical management of potential patients with thoracic disease and anomaly is still lacking. Critical determinants of robust thoracic surgery service provision are pre-existing plans for epidemic response. "Flatten the curve" as an aggressive action is needed. Prioritizations of thoracic surgery cases are needed to differ between elective and emergency cases to limit any contamination. Before surgery, important pre-operative assessments were conducted aims to identify patients' high risk and adjust the procedure. example of a recommendation, if urgent / emergency surgery with symptoms clear clinical pneumonia or rapid test $(+)$. The lessons learned can apply to the other areas during this pandemic, and the world, in preparation for the next one.
\end{abstract}

Keywords: Thoracic surgery preparation, COVID-19 Pandemic, Surabaya experiences

1) Student of Faculty of Medicine, Widya Mandala Catholic University, J1 Kalisari Selatan 1, Surabaya Indonesia. Email : gerardoagung@gmail.com

2) Head of Surgery and Anesthesiology Department Faculty of Medicine, Widya Mandala Catholic University, Kalisari Selatan 1, Surabaya Indonesia

*) President of Indonesia Cardiothoracic and Vascular Surgeon Society

**) President of International College of Surgeon Indonesia Section 


\section{INTRODUCTION}

The first case of 2019 coronavirus disease (COVID-19) caused by the SARS Coronavirus 2 (SARS-CoV-2) was reported in Wuhan, China, precisely around December 2019. It has spread rapidly from China to worldwide. ${ }^{1}$ According to J. Wang et al., Human to human transmission of SARSCoV-2 was established. It has caused coronavirus disease (COVID-19) in over 90,000 people in 72 countries, with a case fatality rate of $2.3 \%$ in China and $1.6 \%$ outside China. ${ }^{2}$ In Indonesia, on July 13, 2020, Indonesia has reported 76.981 confirmed cases of COVID-19, the highest in Southeast Asia. In terms of dead patient numbers, Indonesia ranks sixth in Asia, with 3.656 deaths with a case fatality rate of 4,7 $\%{ }^{3}$ Coronaviruses are single-stranded RNA viruses that are classified into four types. SARS-CoV-2, as well as the previously characterized SARS-CoV, which caused the 2003 SARS pandemic, belongs to the genus of beta coronaviruses. ${ }^{4}$ These viruses show $82 \%$ homology in their genomic sequences and attach to host cells through their spike proteins (SARS-2-S and SARS-S, respectively) binding to angiotensinconverting enzyme 2 (ACE2) as a receptor. Viral fusion with the host cell and then infection follows as a result of cellular cysteine and serine protease-mediated cleavage of SARS-2-S and SARS. ${ }^{5,} 6$ The clinical manifestation of SARS-CoV-2 infection is mostly characterized by respiratory tract symptoms, included fever, dry cough, dyspnea, myalgia, fatigue, and radiographic evidence of pneumonia. Those clinical manifestations can cause complications such as pneumonia and acute respiratory distress syndrome. ${ }^{7,1}$

This virus that caused COVID-19 pandemic has stricken many people, taken many lives, and devastated economies around the world on a massive scale. It has challenged healthcare services worldwide, as human and material resources were mobilized to combat the surging pandemic. ${ }^{8}$ To bend the epidemic curve downwards, we must prevent $50-70 \%$ of possible transmissions. The key points to counter the problem of COVID-19 are isolation of cases, and precautionary selfisolation of contacts, the COVID-19 experience from other countries showed that forcefully. Following a positive test result, that person should be isolated to prevent onward transmission. ${ }^{9}$ In Indonesia, the Medical Association Indonesian General Surgery Specialist (PABI) has also published work guidelines for all members of PABI within performing surgical services, including restrictions on visits to the surgical clinic and surgery postponed. Before surgery, important pre-operative assessments were conducted aims to identify patients' high risk and adjust the procedure. example of a recommendation, if urgent / emergency surgery with symptoms 
clear clinical pneumonia or rapid test $(+)$, patients treated as a patient with supervision use of PPE level 3. ${ }^{10,11}$

The specialty of general thoracic surgery includes the management of serious diseases such as chest wall congenital anomaly, lung cancers, esophageal cancers, mediastinal tumor, chest wall infection, and trauma. Time is fundamental in the successful management of these diseases. Therefore, it is a clinical and ethical necessity to provide adequate care for patients with thoracic surgical conditions, even during the COVID19 pandemic. $^{8}$ The urgency of surgical treatment for such malignancies is arguably greater than in other surgical specialties where elective surgery can be postponed. At the same time, an emergency case surgery remains served in the emergency room as a case emergency state. It is, therefore, a clinical and ethical challenge to provide adequate surgical care for patients with a congenital thoracic anomaly, thoracic cancer, thoracic infection that require surgical intervention, thoracic trauma in the face of stretched resources during the ongoing COVID-19 pandemic. $^{12}$ In conclusion, following the agreed surgical protocol and surgical strategy will provide the best services for patients while protecting medical officers in the COVID-19 pandemic era. Currently, only a few recommendations guidelines have been made on the preparation of perioperative environments to support prompt care to cardiothoracic surgery in times of COVID-19 in Indonesia. This article was made to help cardiothoracic surgeons in Indonesia and all around the world to overcome the COVID-19 challenge, especially in thoracic surgery fields.

\section{THORACIC SURGERY TRIAGE 3 PHASES SCENARIO DURING COVID-19 PANDEMIC}

\subsection{Phase 1}

In this phase, surgery is indicated for patients whose survival rate likely to be not compromised by a surgical delay of three months. In Indonesia, only a few amount of COVID-19-infected patients that went to the hospital. The hospital resources are still capable, with no rapid escalation moment in COVID-19 trajectory. ICU ventilator capacity is available to support whether any complications that need ventilator support such as respiratory failures occurred after thoracic surgery. Patients that likely to require prolonged ICU needs (high-risk patients) are recommended to be deferred. ${ }^{13}$ 
Table 1. Thoracic Surgery Triage in Phase 1 (Adopted and modified from COVID-19 Guidance for Triage Operation for Thoracic Malignancies ${ }^{13}$ )

\begin{tabular}{|c|c|c|}
\hline THORACIC DISEASE & TO OPERATE & NOT TO OPERATE \\
\hline Congenital Anomaly & $\begin{array}{l}\text { Recurrent Pneumonitis in } \\
\text { Congenital Tracheoesophageal } \\
\text { Fistula } \\
\text { - The congenital diaphragmatic } \\
\text { anomaly with respiratory distress } \\
\text { complication and strangulation } \\
\text { Cyanosis, Respiratory Distress, } \\
\text { tension pneumothorax that caused } \\
\text { by all types of congenital } \\
\text { pulmonary anomaly } \\
\text { All congenital anomaly with a } \\
\text { further immediate potential life- } \\
\text { threatening complication }\end{array}$ & 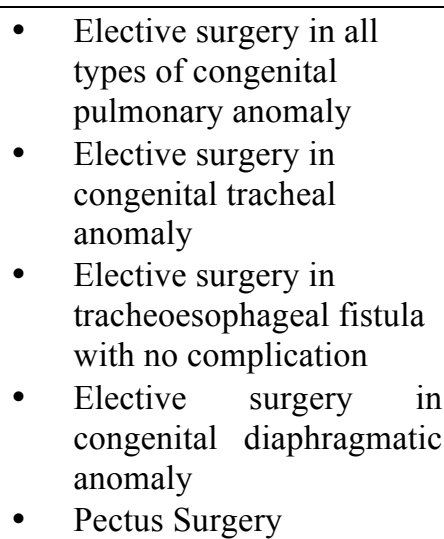 \\
\hline Infection & $\begin{array}{l}\text { Various kinds of thoracic disease } \\
\text { with sepsis cannot be treated with } \\
\text { non-surgical treatment (empyema, } \\
\text { mediastinitis, osteomyelitis, } \\
\text { abscess) with stable or unstable } \\
\text { hemodynamic } \\
\text { Massive hemoptysis with unstable } \\
\text { hemodynamic } \\
\text { Recurrent hemoptysis and lung } \\
\text { fibrotic in Tuberculosis infection }\end{array}$ & $\begin{array}{l}\text { - } \\
\text { Aronchiectasis } \\
\text { thoracic cavity that can be } \\
\text { treated with non-surgical } \\
\text { treatment }\end{array}$ \\
\hline Malignancy & 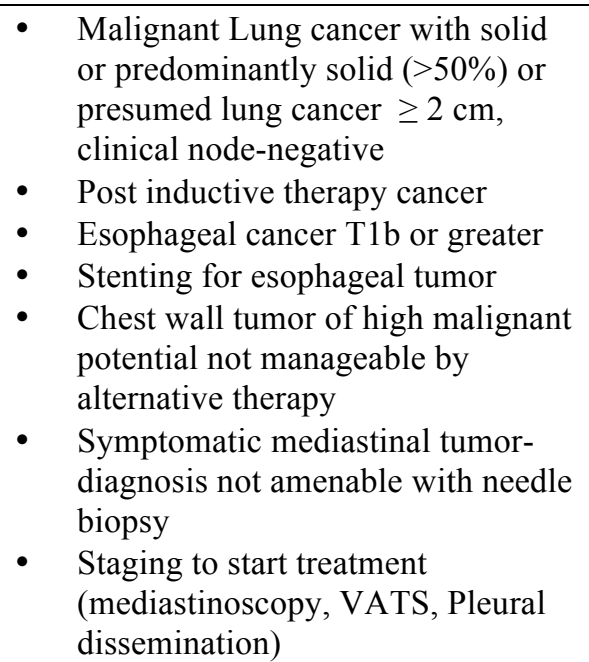 & 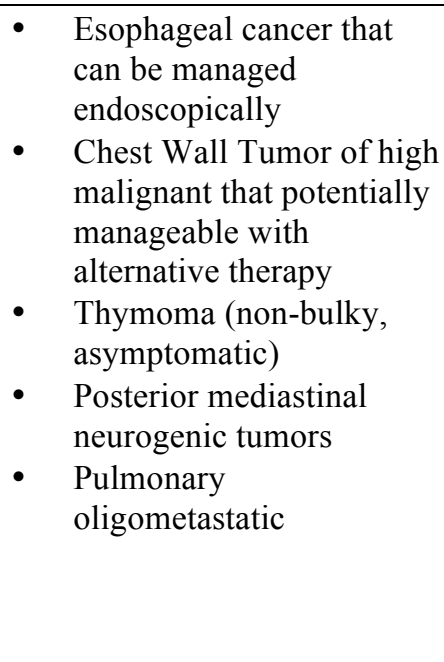 \\
\hline Trauma & $\begin{array}{l}\text { - All trauma cases that need surgical } \\
\text { intervention }\end{array}$ & \\
\hline
\end{tabular}

\subsection{Phase II}

In this phase, surgery is indicated for patients whose survival rate is not compromised if surgery not performed within the next few days. In Indonesia, there are many COVID-19 patients in the hospital with limited resources such as ICU beds ventilators, clinicians, and Personal Protective Equipment (PPE). ${ }^{8}$ COVID-19 trajectory within hospitals is in a rapidly escalating phase. All thoracic procedures typically scheduled as routine/elective, are deferred. ${ }^{13}$ 
Table 2. Thoracic Surgery Triage in Phase 2 (Adopted and modified from COVID-19 Guidance for Triage Operation for Thoracic Malignancies ${ }^{13}$ )

\begin{tabular}{|c|c|c|}
\hline THORACIC DISEASE & TO OPERATE & NOT TO OPERATE \\
\hline Congenital Anomaly & $\begin{array}{l}\text { Recurrent Pneumonitis in } \\
\text { Congenital Tracheoesophageal } \\
\text { Fistula } \\
\text { The congenital diaphragmatic } \\
\text { anomaly with respiratory distress } \\
\text { complication and strangulation } \\
\text { Cyanosis, Respiratory Distress, } \\
\text { tension pneumothorax that caused } \\
\text { by all types of congenital } \\
\text { pulmonary anomaly }\end{array}$ & 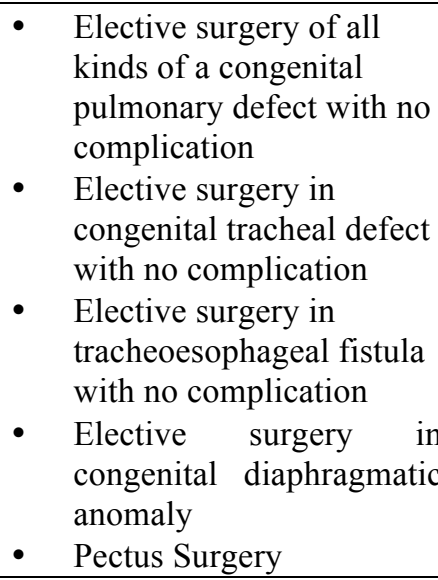 \\
\hline Infection & $\begin{array}{l}\text { All type of thoracic infection with } \\
\text { sepsis, cannot be treated with non- } \\
\text { surgical treatment with unstable } \\
\text { hemodynamic }\end{array}$ & $\begin{array}{l}\text { - } \\
\text { Bronchiectasis } \\
\text { - } \quad \text { Aost-operative minor } \\
\text { the thoracic cavity that } \\
\text { can be treated with non- } \\
\text { surgical treatment } \\
\text { The thoracic disease that } \\
\text { can be drained by chest } \\
\text { tube } \\
\text { Pneumothorax for } \\
\text { pleurodesis }\end{array}$ \\
\hline Malignancy & $\begin{array}{l}\text { - Lung cancer-associated infection- } \\
\text { compromising but not septic } \\
\text { - } \quad \text { Lung cancer-associated with } \\
\text { hemorrhage not amenable to non- } \\
\text { surgical treatment } \\
\text { - } \quad \text { Lung cancer with threatened airway } \\
\text { - Septic and non-septic perforation in } \\
\text { esophageal cancer }\end{array}$ & 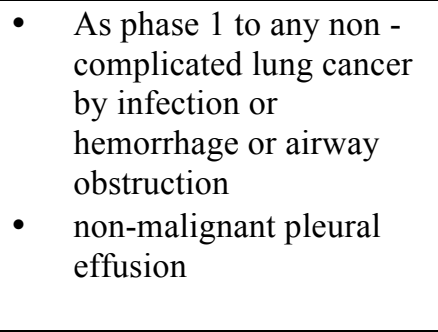 \\
\hline Trauma & $\begin{array}{l}\text { - All thoracic trauma cases with a } \\
\text { life-threatening condition (e.g., } \\
\text { significant airway injury, airway } \\
\text { obstruction by an inhaled foreign } \\
\text { body, pneumothorax, flail chest, } \\
\text { penetrating chest injury, massive } \\
\text { hemothorax) } \\
\text { Retained bullets with fear of } \\
\text { migration and embolization }\end{array}$ & $\begin{array}{l}\text { - All thoracic trauma cases } \\
\text { that can be treated } \\
\text { conservatively } \\
\text { Retained bullet with no } \\
\text { fear of migration and } \\
\text { embolization }\end{array}$ \\
\hline
\end{tabular}

\subsection{Phase III}

In this phase, surgery is indicated for patients whose survival rates are not compromised if surgery not performed within the next few hours. Hospital resources are critically limited and predominately routed to COVID-19 patients. All non-emergent operations are deferred. 
Table 3. Thoracic Surgery Triage in Phase 3 (Adopted and modified from COVID-19 Guidance for Triage Operation for Thoracic Malignancies ${ }^{13}$ )

\begin{tabular}{|c|c|c|}
\hline THORACIC DISEASE & TO OPERATE & NOT TO OPERATE \\
\hline Congenital Anomaly & $\begin{array}{l}\text { - All types of congenital anomaly } \\
\text { with immediate life-threatening } \\
\text { condition complications }\end{array}$ & $\begin{array}{l}\text { - All kinds of a congenital } \\
\text { anomaly with no } \\
\text { immediate life-threatening } \\
\text { condition complications }\end{array}$ \\
\hline Infection & $\begin{array}{l}\text { All thoracic type of disease with an } \\
\text { immediately life-threatening } \\
\text { condition that can not be treated } \\
\text { with a non-surgical approach }\end{array}$ & $\begin{array}{l}\text { All kind of thoracic that } \\
\text { can be treated with a non- } \\
\text { surgical approach }\end{array}$ \\
\hline Malignancy & $\begin{array}{ll}\text { - } & \text { Lung Cancer with threatened } \\
\text { airway } \\
\text { - } & \text { Lung Cancer with tumor-associated } \\
\text { infection } \\
\text { - } \quad \text { Lung cancer with tumor-associated } \\
\text { hemorrhage and hemodynamically } \\
\text { unstable } \\
\text { Esophageal cancer with septic } \\
\text { perforation }\end{array}$ & $\begin{array}{l}\text { - All types of cancer with } \\
\text { no life-threatening } \\
\text { condition }\end{array}$ \\
\hline Trauma & $\begin{array}{l}\text { - All thoracic trauma cases with a } \\
\text { life-threatening condition (e.g., } \\
\text { significant airway injury, airway } \\
\text { obstruction by an inhaled foreign } \\
\text { body, pneumothorax, flail chest, } \\
\text { penetrating chest injury, massive } \\
\text { hemothorax) }\end{array}$ & $\begin{array}{l}\text { All thoracic trauma cases } \\
\text { that can be treated } \\
\text { conservatively } \\
\text { Thoracic trauma with no } \\
\text { life-threatening condition }\end{array}$ \\
\hline
\end{tabular}

\section{SURGERY PREPARATION}

\subsection{Patient Screening}

Most of the thoracic surgical cases are performed for a prognostic reason. The procedure's timing will depend on between patient's benefit and risk of getting infected by COVID-19, resource availability, and hospital rules. Surgical services for patients with thoracic problems (congenital anomaly, infection, benign and malignant tumor, trauma) were maintained to different procedures/protocols across various countries, ranging from significant reductions to nearnormal service depends on many COVID-19 cases. Strict and precise protocols are needed to protect medical personnel from exposure to the COVID-19 virus during the thoracic surgery process. This protocol is important, especially in emergency cases requiring immediate action, without prior knowledge of the patient's medical history. Table 4 shows a scoring system that can be used in patients with a high degree of urgency (without waiting for rapid test results in advance) to determine the suspicion of COVID-19, which will be associated with surgical preparation. Figure 1 shows the flow of surgical decision making in an emergency or elective patients who have confirmed positive COVID-19 through rapid tests. ${ }^{10,12,14}$ 


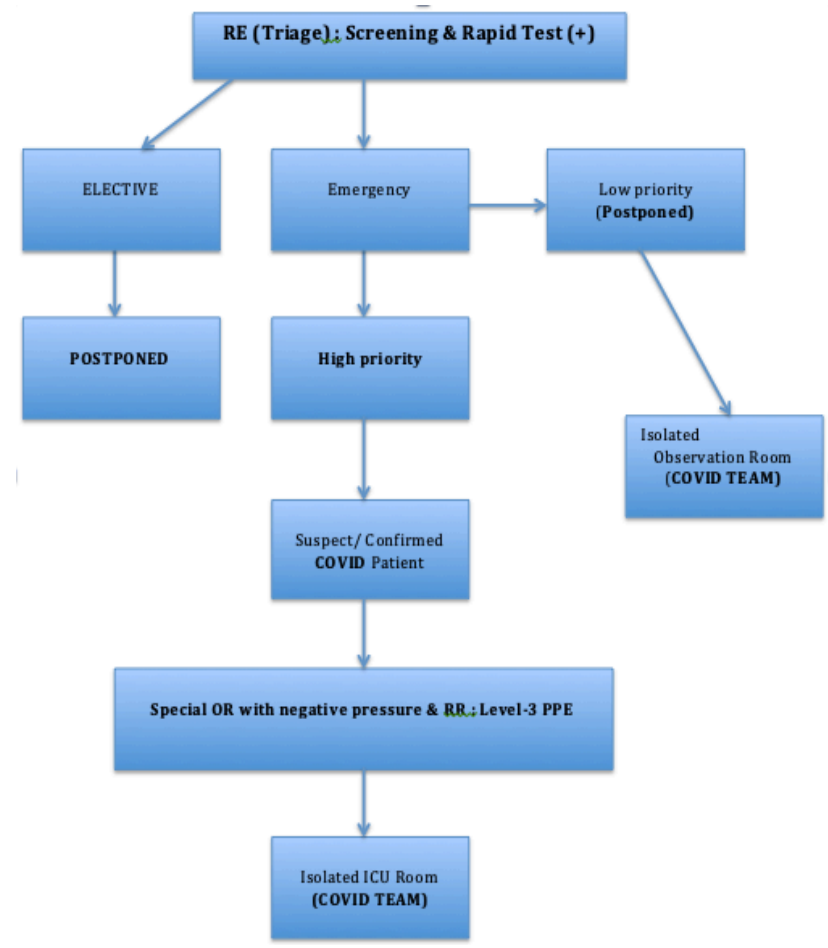

Figure 1. Screening Protocol for Elective and Emergency Surgery in Confirmed COVID-19 Patient (Adapted and modified from Adihusada Private Hospital Surabaya)

Table 4. Scoring System for Surgery Preparation (Adapted and Modified from Adihusada Private Hospital Surabaya)

\begin{tabular}{|c|c|c|}
\hline PARAMETERS & ASSESSMENT & SCORE* \\
\hline $\begin{array}{c}\text { Pneumonia on CT Scan } \\
\begin{array}{c}\text { Contact history with COVID-19 } \\
\text { positive patient }\end{array}\end{array}$ & Exist & 5 \\
\hline $\begin{array}{c}\text { Fever / History of fever in the past } 14 \\
\text { days }\end{array}$ & Exist & 3 \\
\hline $\begin{array}{c}\text { Desaturation } \\
\text { AGE }\end{array}$ & $\begin{array}{c}\text { SpO }_{2} \leq 95 \% \text { without oxygen } \\
\text { supplementation }\end{array}$ & 1 \\
\hline Gender & $\geq 44$ years old & 1 \\
\hline $\begin{array}{c}\text { Respiratory disorder symptoms } \\
\text { cough, runny nose, blown, etc. }\end{array}$ & Male & 1 \\
\hline Neutrophil - lymphocyte ratio & $\geq 3,13$ & 1 \\
\hline \multicolumn{2}{|c|}{ Total symptom } & \\
\hline
\end{tabular}

Total Score $>10 \rightarrow 3^{\text {rd }}$ level Personal Protective Equipment (PPE)

Lab test: Complete blood, CRP, Rapid test

\subsection{Anesthesia Preparation}

In managing patients with confirmed or suspected COVID-19 infection, of course, planned in conjunction with protection for the health care workers. All medical practitioner must be provided with personal protective equipment (PPE) to prevent droplet and contact infections. Before patient treatment, the practitioner must identify and review the hospital procedural protocols, and plan for patient transfer, anesthesia work environment, 215 and anesthesia methods. ${ }^{15}$ The COVID-19 pandemic does not eliminate cardiothoracic cancer and cardiothoracic trauma surgery. There is a possibility of unavoidable intraoperative aerosol-generating procedures in the routine provision of thoracic anesthesia. Suggestions for increased severity of illness for those exposed to high viral loads have been given, and aerosol-generating procedures are concerning those involved with airway management. There are special 
condition to consider in terms of lung isolation, which require great attention to reduce the risk of aerosol generation. ${ }^{16}$ Aerosol-generating procedures encountered routinely in thoracic anesthesia include: bagvalve-mask ventilation, tracheal intubation, tracheal tube repositioning, bronchoscopy; one-lung ventilation, suction clearance of secretions, and the management of hypoxia during one-lung ventilation. ${ }^{17}$

\subsubsection{Tracheal Intubation}

The patient should be adequately preoxygenated for $3 \mathrm{~min}$ or until the end-tidal oxygen fraction is greater than 0.9 . The target is to achieve sufficient apneic time to allow safe intubation without the need for bagvalve-mask ventilation. ${ }^{18} \mathrm{~A}$ modified rapid sequence tracheal intubation using high dose rocuronium is a must for the anesthetic technique. Facemask ventilation should be avoided where possible, and a two-person technique should be used where necessary. Tracheal intubation should be followed immediately by cuff inflation, circuit connection, and ventilation of both lungs. ${ }^{16}$ Confirmation in terms of the position of double-lumen tubes involves the use of a flexible bronchoscope to visualize the endobronchial cuff and its relation to the carina directly. If there is a clinical preference to avoid bronchoscopy, it is possible to perform clinical confirmation of positioning, thus preventing disconnection of the breathing circuit. $^{17}$

Following tracheal intubation with a left-sided double-lumen tube, clinical confirmation should start with no clamp applied and bilateral air entry confirmed with manual ventilation. As soon as the two-way air entry is achieved, a clamp should be applied to the angle piece supplying the tracheal lumen. If the double-lumen tube is positioned correctly, there should be leftsided air entry only. If bilateral ventilation extends, the distal end of the tracheal tube or the bronchial cuff is above the carina, then, deflate only the bronchial cuff and advance the tracheal tube until there is resistance, reinflate the bronchial cuff and repeat the steps above. Bronchoscopy will be required to troubleshoot placement if there is resistance to advancing the tracheal tube or if it is still not possible to confirm the correct placement clinically. When the tracheal tube is placed correctly, the patient should be positioned for surgery. The checking process should be repeated after positioning laterally to ensure the tracheal tube position has not changed. ${ }^{17}$ 

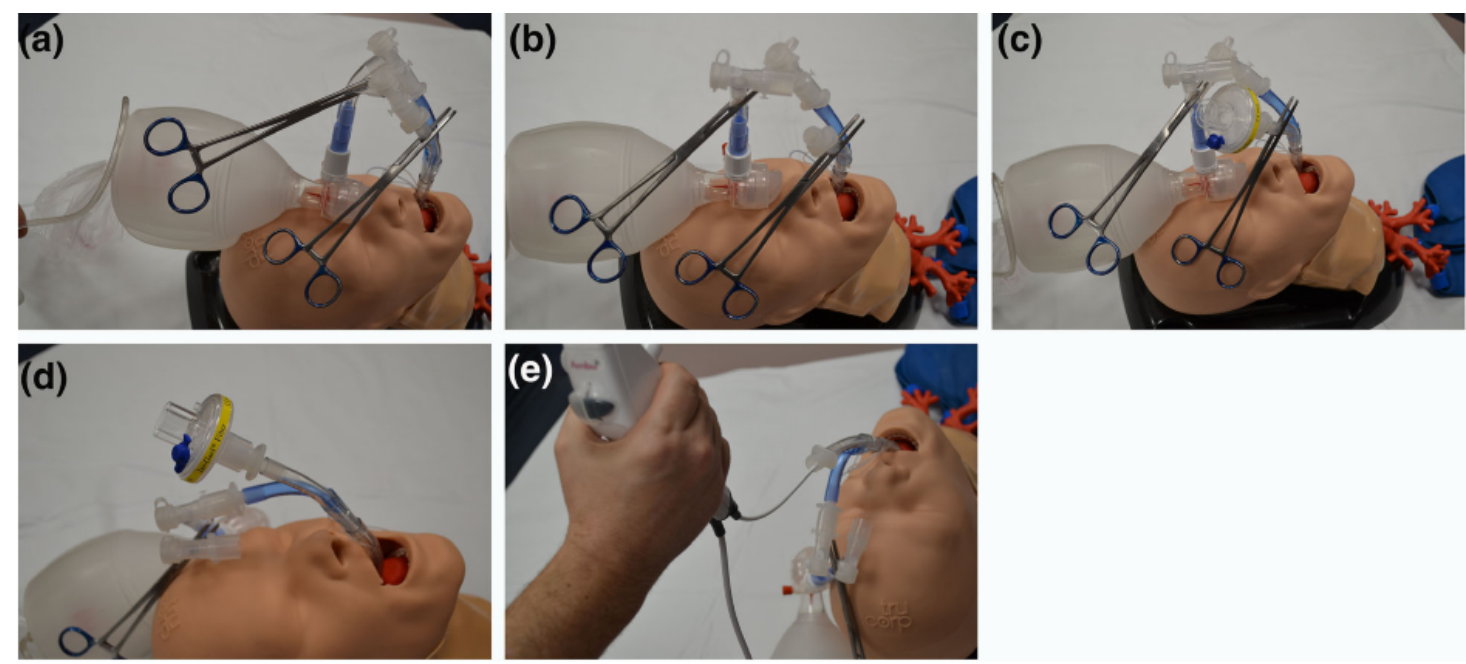

Figure 2. Mannequin images demonstrating

(a) the clamp applied to tracheal lumen angle piece and double-lumen tube; (b) disconnection without pollution; (c) using a HEPA viral filter to tracheal lumen; (d) removing the clamp to allow positive pressure from the lung to vent through HEPA viral filter; and (e) removing the HEPA viral filter and performing bronchoscopy. ${ }^{17}$

\subsubsection{Lung Isolation}

Some measures can attain lung isolation. Left or right-sided double-lumen tubes (DLT), bronchial blockers (BB), or a single lumen tube (SLT) advanced into the non-operative lung are the options. The European Association of Cardiothoracic Anaesthesiology (EACTA) has announced recommendations for airway management in thoracic anesthesia. A survey conducted by EACTA showed that lung isolation management options are likely to be affected by the intubation status of the patient, predicted airway difficulty, and individual preference. $^{19}$ The main threat of environmental contamination, once the airway is secured and with surgery underway, is the disconnection of the lumen of the nondependent lung. This can be mitigated against by allowing the lung to deflate through a high-efficiency particulate air (HEPA) viral filter. Furthermore, the continued application of a HEPA viral filter to the open lumen will protect against any perioperative loss of lung isolation. A leak of any ventilated gas into the open lumen causes environmental pollution and contamination. The patient should be immediately positioned, surgery commenced, and lung isolation required. The neuromuscular blockade should be adequate. The adjustable pressure-limiting valve open and ventilation discontinued before the surgical lumen of the double-lumen tube and the arm of the angle piece serving this lumen are clamped. The arm of the angle piece should be disconnected, and a HEPA viral filter applied to the double-lumen tube's surgical lumen. The clamp is then removed from the double-lumen tube's surgical lumen to facilitate the collapse of the non-dependent lung through the HEPA viral filter. ${ }^{17}$

\subsubsection{One Lung Ventilation}

Another option is to confirm lung ventilation with ultrasound, looking for lung sliding (ventilation) and absence of lung sliding and lung pulse (no ventilation but no 
pneumothorax). ${ }^{19} \quad$ For these recommendations, it is assumed that all other measures to address hypoxia have been considered, and the diagnosis is that of shuntdriven hypoxia. Although two-lung ventilation is always the default position for critical hypoxia during one-lung ventilation, shunt-driven hypoxia can often be overcome by administering oxygen to the nondependent lung. ${ }^{20}$ The simplest method of administering oxygen to the operative lung is via insufflation through a suction catheter through the double-lumen tube's open lumen. $^{21}$ This nevertheless carries an unacceptable risk of aerosol generation. Instead, using a continuous positive airway pressure circuit with a HEPA viral filter is the recommended method. Standard practice, constant positive airway pressure should be titrated until there is clinical improvement. ${ }^{17}$
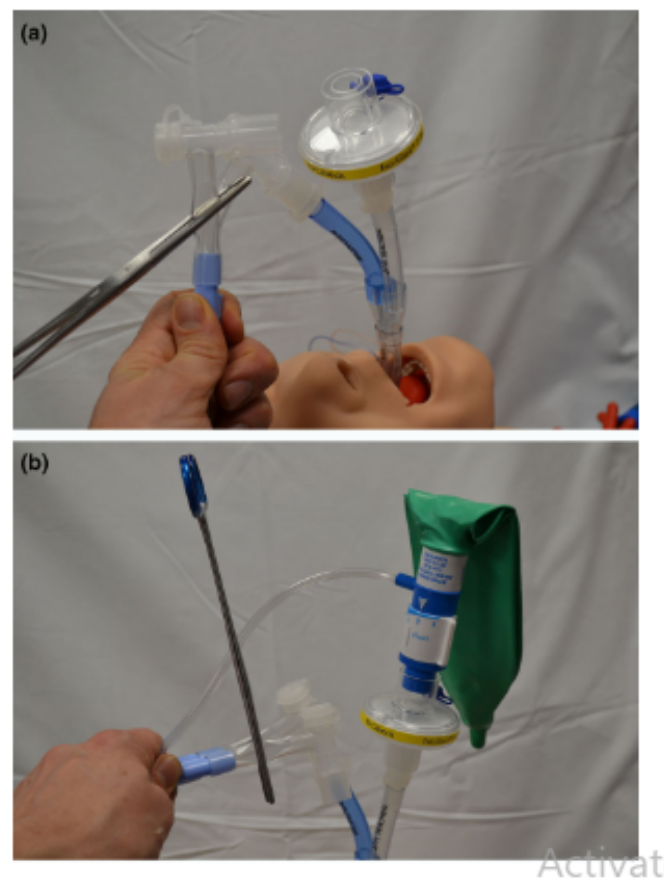

Figure 3. Mannequin images demonstrating

(a) HEPA viral filter in place on the double-lumen tube's surgical lumen and (b) a continuous positive airway pressure circuit safely applied. ${ }^{17}$

\subsection{Personal Protective Equipment}

Personal protective equipment

(PPE) is a device designed as a barrier against the penetration of substances, solid particles, liquid, or air to protect the wearer from injury or spread of infection or disease. When appropriately used, PPE acts as a barrier between infectious material (e.g., viruses and bacteria) and the skin, mouth, nose, or eyes (mucous membranes) of health workers and patients. $^{22,23}$ Barriers have the potential to block the transmission of contaminants from blood, body fluids, or respiratory secretions. Effective use of PPE involves the removal and/or disposal of PPE that is adequately contaminated to prevent the exposure of users and others to infectious material. In selecting the correct PPE, it is necessary to identify the 
potential exposure to infectiousness and understand the basis for each type of PPE work that will be used in the workplace where the potential danger threatens healthcare workers in the hospital. All PPE used must comply with applicable consensus standards. ${ }^{2,22}$

Thoracic surgery is a high-risk procedure. Asymptomatic patients without a confirmed negative COVID-19 Rapid Test PCR test within four days undergoing thoracic surgery, all team members must don full contact, droplet, and airborne PPE (N95 respirator with face shield/goggles or PAPR plus gown and double gloves) for the entire duration of the case. For asymptomatic patients with a confirmed negative COVID19 RT-PCR test obtained within four days of the procedure, standard PPE and pre-COVID workflows can be used for any type of surgery (scenario 5). All providers can remain in the room during an aerosol-generating medical procedure (AGMP) and do not need to wait any specified time after an AGMP before allowing entry into the room or exiting a location. ${ }^{10}$

\subsection{Operating Room Theater}

Operating room (OR) for patients with suspected/confirmed COVID-19 should differ from normal OR. The most important is to ensure that the airborne particle does not leak out of the rooms with COVID-19-infected patients. It should be designed starting from the protocol for patient flow to and from the OR. An OR with negative pressure or neutral is preferred to prevent any spread of infection and protect healthcare workers. The negative pressure created by placing 2-3 exhaust fans that will drive air out of the room. The OR should be located in dedicated buildings for COVID, near the COVID ICU, Emergency Ward, and Isolation Ward. Only important and essentials items should be inside the operating room and separated between surgical equipment, linen and dressing, and anesthesia. Monitors, cables, cautery, operation table, etc., should be covered with water-resistant and transparent plastic, which should be removed from every post-surgery. There should be minimum personnel inside COVID OR consist: 1) 2 Surgeons (1 if feasible); 2) 1 Nurse ; 3) 1 Anaesthesiologist; 4) 1 Anaesthesiology technician; 5) 1 Sweeper. ${ }^{2,11 \text {, }}$

\section{REFERENCES}

1. Lei, S. et al. Clinical characteristics and outcomes of patients undergoing surgeries during the incubation period of COVID-19 infection. EClinicalMedicine 21, 100331 (2020).

2. Wong, J. et al. Preparing for a COVID19 pandemic: a review of operating room outbreak response measures in a large tertiary hospital in Singapore. Can. J. Anesth. 67, 732-745 (2020).

3. Covid19.go.id. Peta Sebaran. (2020).

4. Flemming, S. et al. Surgery in times of COVID-19-recommendations for hospital and patient management. Langenbeck's Arch. Surg. 405, 359364 (2020).

5. Chan, J. F. W. et al. Genomic characterization of the 2019 novel human-pathogenic coronavirus isolated from a patient with atypical pneumonia after visiting Wuhan. Emerg. Microbes 
Infect.

(2020).

doi:10.1080/22221751.2020.1719902

6. M., H. et al. SARS-CoV-2 Cell Entry Depends on ACE2 and TMPRSS2 and Is Blocked by a Clinically Proven Protease Inhibitor. Cell (2020).

7. Inciardi, R. M. et al. Cardiac Involvement in a Patient with Coronavirus Disease 2019 (COVID19). JAMA Cardiol. 2019, 1-6 (2020).

8. Jheon, S. et al. General thoracic surgery services across Asia during the 2020 COVID-19 pandemic. Asian Cardiovasc. Thorac. Ann. 28, 243-249 (2020).

9. Marcel, S. et al. COVID-19 epidemic in Switzerland: On the importance of testing, contact tracing and isolation. Swiss Med. Wkly. 150, 4-6 (2020).

10. Persatuan Ahli Bedah Indonesia. Surat Nomor 30/PP-PABI/III/2020 Pelayanan Bedah Pada Era Pandemi COVID-19 tanggal 21 Maret 2020. in (Persatuan Ahli Bedah Indonesia, 2020).

11. Ti, L. K., Ang, L. S., Foong, T. W. \& $\mathrm{Ng}, \mathrm{B}$. S. W. What we do when a COVID-19 patient needs an operation: operating room preparation and guidance. Can. J. Anesth. 67, 756-758 (2020).

12. Jheon, S. et al. Thoracic cancer surgery during the COVID-19 pandemic: A consensus statement from the Thoracic Domain of the Asian Society for Cardiovascular and Thoracic Surgery. Asian Cardiovasc. Thorac. Ann. $218492320940162 \quad$ (2020). doi:10.1177/0218492320940162

13. Boffa, D. J. COVID-19 Guidance for Triage of Operations for Thoracic Malignancies: A Consensus Statement from Thoracic Surgery Outcomes Research Network. Ann. Thorac. Surg. (2020). doi:10.1016/j.athoracsur.2020.03.005

14. Besnier, E., Tuech, J. J. \& Schwarz, L. We Asked the Experts: Covid-19 Outbreak: Is There Still a Place for Scheduled Surgery? "Reflection from Pathophysiological Data". World J. Surg. 44, 1695-1698 (2020).

15. Kim, H. J., Ko, J. S. \& Kim, T.
Recommendations for anesthesia in patients suspected of COVID-19 Coronavirus infection. 4-6 (2020).

16. Cook, T. M. et al. Consensus guidelines for managing the airway in patients with COVID-19: Guidelines from the Difficult Airway Society, the Association of Anaesthetists the Intensive Care Society, the Faculty of Intensive Care Medicine and the Royal College of Anaesthetists. Anaesthesia 75, 785-799 (2020).

17. Thornton, M., Reid, D., Shelley, B. \& Steven, M. Management of the airway and lung isolation for thoracic surgery during the COVID-19 pandemic. Anaesthesia (2020). doi:10.1111/anae.15112

18. Li, W., Huang, J., Guo, X., Zhao, J. \& Mandell, M. S. Anesthesia Management and Perioperative Infection Control in Patients With the Novel Coronavirus. J. Cardiothorac. Vasc. Anesth. 000, 1-6 (2020).

19. Prince, R., Hospital, A., Wales, N. S. $\&$ Pavey, W. The Medical Journal of Australia - Pre-print - 29 June 2020. (2020).

20. Rozé, H., Lafargue, M. \& Ouattara, A. Case scenario: Management of intraoperative hypoxemia during onelung ventilation. Anesthesiology 114, 167-174 (2011).

21. Jung, D. M. et al. Apneic oxygen insufflation decreases the incidence of hypoxemia during one-lung ventilation in open and thoracoscopic pulmonary lobectomy: A randomized controlled trial. J. Thorac. Cardiovasc. Surg. 154, 360-366 (2017).

22. Brücher, B. L. D. M. et al. COVID-19: Pandemic surgery guidance. 4Open $\mathbf{3}$, 1 (2020).

23. American College of Surgeons. COVID 19: Elective Case Triage Guidelines for Surgical Care. Am. Coll. Surg. March 24, 2020 (2020). 